\title{
A Critical Evaluation of Telecommunication Act 1996
}

\author{
Kashif Azim Janjua, Sahibzada Ahmed Noor and Shahzada Alamgir Khan
}

School of Economics and Management Beijing University of Posts and Telecommunications, Beijing 100876, China

\begin{abstract}
Telecommunication Act 1996 was considered as a milestone in the history of US telecommunication sector, as it aimed at breaking monopoly in local telecommunication market and creating competition. During last 10 years, the pace of competition in local telephony market has been very slow. Baby Bells still hold a strong dominance and a near monopoly position. They have even spread their monopoly to long distance market by mergers and acquisitions. This shows the failure of the Act. Local monopoly breaking policy, vertical reintegration, universal service and UNE pricing are the major reasons of this failure. Local loop is a natural monopoly and further investment by multiple companies is not efficient. Idea of universal service should be dropped.
\end{abstract}

Keywords: telecom act 1996, Vertical Integration, Universal Service.

\section{Introduction}

The local telephone industry was thought to be naturally prone to monopoly as a consequence of massive scale and scope economies in provision of services over wire line networks [1-3]. Until the last quarter of $20^{\text {th }}$ century, in USA, telecom sector was a regulated one with a single monopoly company American Telephone and Telegraph (AT\&T). In 1945 AT\&T had an almost monopoly over the sector, owning more than $80 \%$ of the lines and equipment used in USA [4, 5]. In 1934 the first Telecommunication Act was passed by Congress [6], which crystallized the regulatory superstructure and created the Federal Communication Commission (FCC) [7]. In 1969, Microwave Communication Inc. (MCI) was granted permission to provide leased line services [8]. The divestiture of AT\&T in 1984 [9] led to the creation of seven independent Regional Bell Operating Companies (RBOCs) and one long distance company AT\&T [10,11]. RBOCs were regional monopolies in their areas while AT\&T faced competition mainly from MCI and Sprint [12]. As a result of divestiture RBOCs were not allowed to enter the long distance market and AT\&T lost its direct access to consumers.

Until 1996, digitization, mobile communication and convergence of information, video and communication technologies had been understood by the government [13, 14]. The government decided to introduce competition in the local telephony market and Congress passed an Act which is known as Telecommunication Act 1996. The Act proposed changes to convert monopoly in local telephony market into competition. The preamble clearly and succinctly articulates the goal of the Act [15].

“An Act To promote competition and reduce regulation in order to secure lower prices and higher quality services for American telecommunications consumers and encour- age the rapid deployment of new telecommunications technologies."

The rest of paper is organized as follows: Section II documents the goals of Telecom Act and the strategy it used to achieve its goals. In Section III, an analysis based on data collected from FCC is provided. The objective is to find out the present condition of the market. Some fallouts of the act are given is section IV. An analysis of 14 point check list is done in section V. In section VI results of section III, IV and V are summarized. Section VII discusses the reasons of the failure. Section VIII provides a summary and the conclusion of the study. Finally, references are given at the end.

\section{Goals of Telecom ACT 1996}

The Telecommunication Act of 1996 was a second major restructuring of the US Telecommunication sector after 1934 Act. Congress took radical steps to restructure US Telecommunication markets by passing the Act [16]. Three major goals of the Act can be stated as follows.

- The prime goal of the Act was the creation of competition in the local telephony market.

- The second goal of the Act was to increase investment in local infrastructure by creating competition.

- The third goal was to achieve of universal service.

Strategy of the Act

The Act tries to create competition in three ways.

(i) Reselling

(ii) Unbundled Access

(iii) New Entry (full facilities based)

Reselling eases entry in the retail business, by requir- 
ing Incumbent Local Exchange Carriers (ILECs) to sell services to new entrants at wholesale prices. Such entry is limited only to the retailing side of the market. The most significant means of entry is through leasing of unbundled network elements from incumbents. It mandates interconnection, unbundling and non discrimination to boost competition and reduce artificial barriers to entry. Competitors can enter easily by purchasing Unbundled Network Element (UNEs) or by constructing their own infrastructure. In this way they can compete component by component and service by service.

The Act imposes conditions to ensure de facto monopoly power is not exported to vertically related markets. Thus the Act tries to ensure the competition is created in local market before allowing RBOCs to enter in the long distance market. The Act allows RBOCs to enter in the long distance market segment only after fulfilling a list of 14 requirements.

\section{Analysis of the Present Market Situation}

To judge the success of Telecom Act 1996, it is necessary to find the success of different strategies used. To analyze the effects of these strategies, following questions are analyzed here.

1. What portion of the market is captured by Competitive Local Exchange Carriers (CLECs)?

2. What technologies are used by CLECs?

3. How an average consumer is affected by the Act?

First question will provide the status of competition in local market. Second question will decide about the success of approaches used by FCC to introduce competition. Third question will throw light whether subscribers have gained benefits of the rapid technological advancements. Data used in this analysis is primarily taken from FCC.

\subsection{Market Share}

Figure 1 [16] shows the number of ILEC and CLEC enduser switched access lines from December 1999 to December 2005. CLECs provided only 31.5 million (or 18\%) of the approximately 215 million nationwide switched access lines in service to end user customers at the end of December 2005. Figure 3 [16] is the graphical representation of percentage CLEC share over the years. The increase in lines shows the slow pace of competition in the market. It is also evident from this figure that major share of market is still held by ILECs.

Figure 2 [17] shows the market share of CLECs and ILECs. This is based on ILEC and CLEC share of local service revenues from 1998 to 2003. CLECs could increase their share of revenue to only $15 \%$ of the total revenue. This is really a small portion as compared to the revenue of ILECs.

Figure 4 [16] gives an account of the popularity of three different techniques used by FCC to attain competition. As evident that owned capacity by CLECs has been almost the same, thus showing that no serious investment in infrastructure has been made. Resale has decreased dramatically where as Unbundled Network Element (UNEs) purchase has increased a lot. This show with the time negotiations between companies about unbundled access is easing out making it most successful approach. Also resale has not gained popularity.

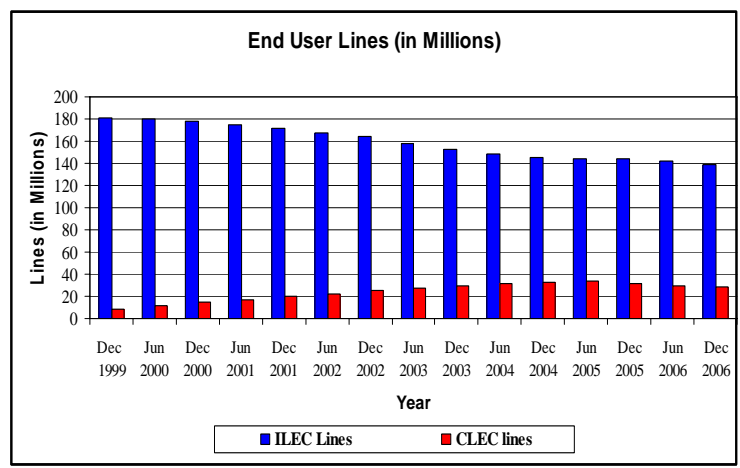

Figure 1. CLEC Vs. ILEC Share

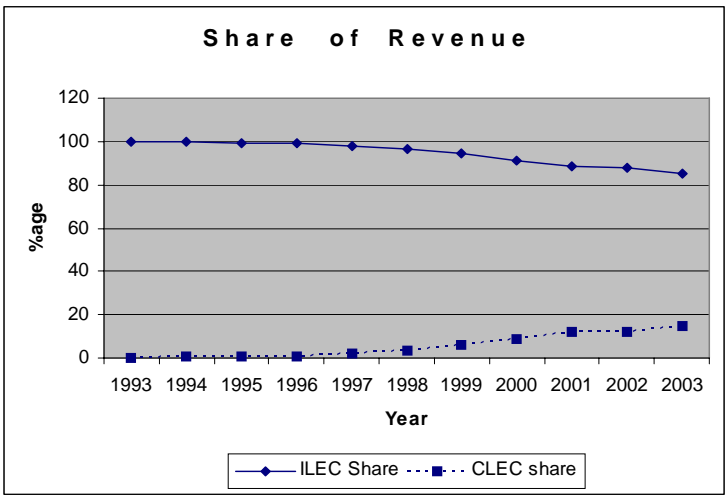

Figure 2. CLEC Vs. ILEC Share of Revenue

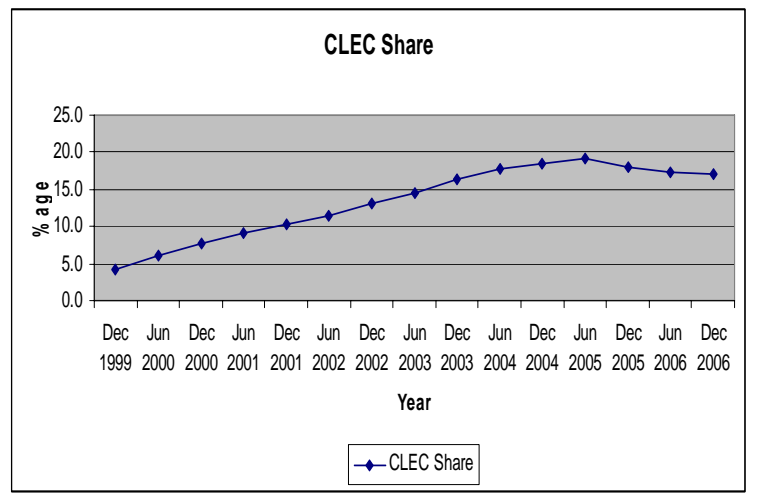

Figure 3. Percentage CLEC share of lines

\subsection{Comparison of technologies}

Figure 5 [16] shows that FCC's approach of enticing coaxial companies has also failed as only 16\% of CLEC's 
network is coaxial based. Coaxial cable has failed as a substitute to copper pair in local loop. Figure 6 [16] show the distribution of lines of CLECs and ILECs. In the beginning CLECs only concentrated on business lines but now slowly they are moving their direction towards the bigger portion of the society, that is, the residential subscriber. Slowly their percentage share of residential subscribers has increased.

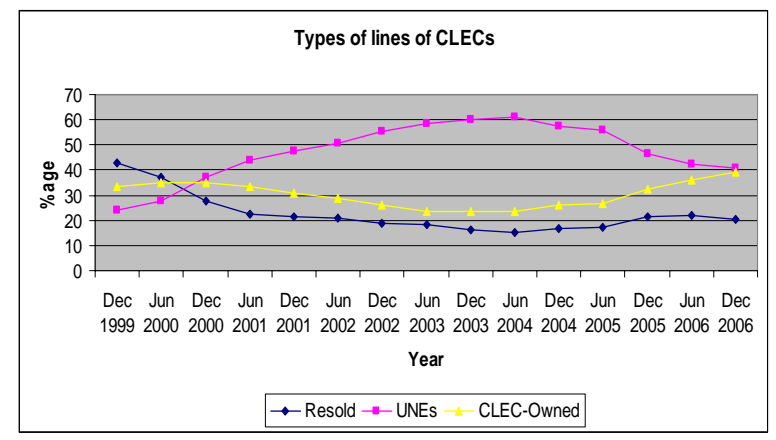

Figure 4. Types of lines of CLECs

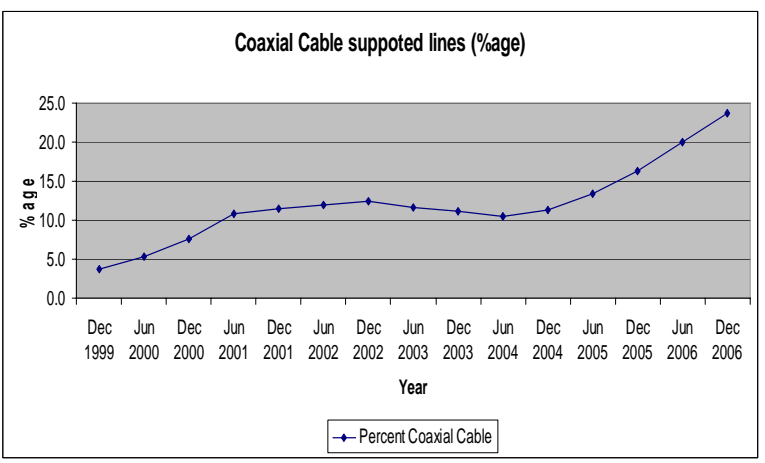

Figure 5. Percentage of coaxial supported lines

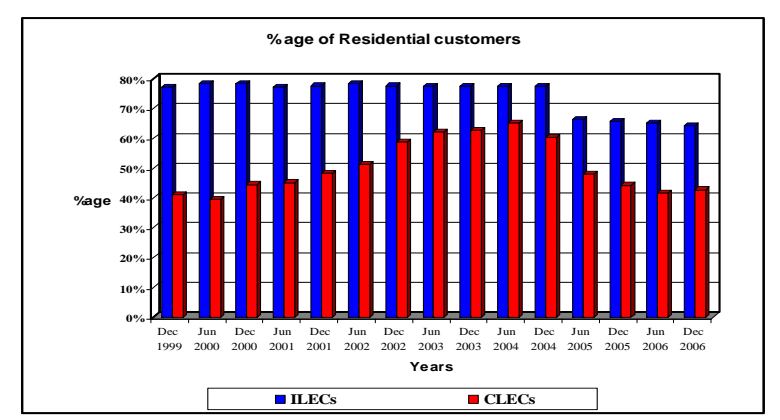

Figure 6. Percentage of residential customers

\subsection{Consumer expenditure}

Figure7 [17] presents an average household spending on telecom services. As evident that the expenditure of local services has increased where as the international service expenditure has decreased quite a bit. In international market there is quite a bit competition giving the benefits directly to consumers.

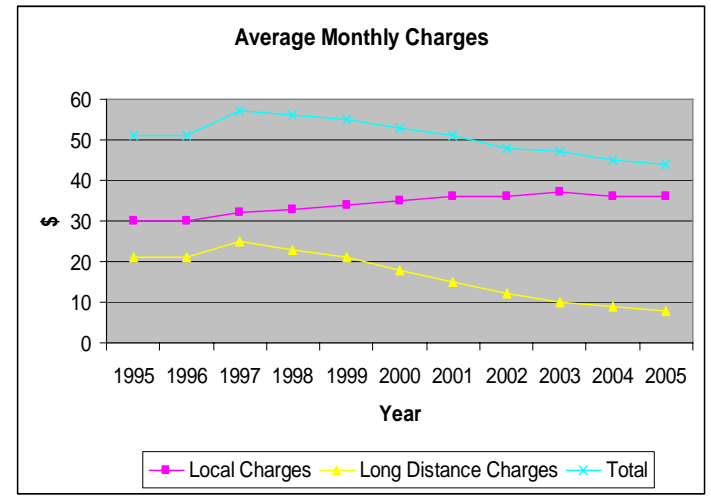

Figure 7. Average Monthly Charges

\section{Fallouts of the ACT}

Following fallouts of the Act are evident from today's market.

\section{Vertical reintegration}

The Act allowed local telephone companies to offer long distance service but to provide such service in their area they have to fulfill their commitment of creating competition in the area. The Act included a checklist of 14 points for RBOCs to fulfill before their entry into Inter LATA services [18]. The opportunity of allowing RBOCs an entry in long distance market was not a successful strategy. This allowed RBOCs to again enter in the long distance markets. Problems arise, when a telecommunication carrier with monopoly or near monopoly power in the provision of a particular facility also offers a competitive service that is dependent upon the use of the monopoly facility. These problems are cross subsidization and discrimination. The Act allowed RBOCs to monopolize using these methods. They acted in the same direction. The result was a wave of mergers and acquisitions.

\section{Mergers and Acquisitions}

Mergers especially vertical ones are enemies of the competition as they kill the concept of co-operation. Vertical Mergers can squeeze other companies and create monopoly in the market. Earlier, in the absence of entry in the local exchange market as envisioned by the Act, the major long distance companies bought companies that gave them some access to the local market.

For example, MCI merged with WorldCom, which had just merged with Brooks Fiber and MFS, which in turn also own some infrastructure in local exchange markets. AT\&T unveiled an ambitious strategy of reaching consumer homes by using cable TV wires for the last mile. With this purpose in mind, AT\&T bought TCI and in April 1999 AT\&T outbid Comcast and acquired MediaOne, the cable spin-off of US West. AT\&T also acquired TCG, which owned local exchange infrastructure 
that reached business customers. All such mergers and acquisitions tarnished the image of a fully competitive telecom market.

\section{Re-monopolization by RBOCs}

Attempts by the RBOCs to maximize their foothold include SBC's acquisition of Pacific Bell and Ameritech, and Bell Atlantic's merger with NYNEX. SBC also bought Southern New England Telephone (SNET). Bell Atlantic has merged with GTE, creating Verizon.

Thus, the 8 large local exchange carriers of 1996 (7 RBOCs and GTE) are reduced to only 4: Verizon, Bell South, SBC, and US West. US West recently merged with Qwest. SBC first bought AT\&T in 2005 and then recently it has merged with Bell South leaving just three major companies in local telephony.

Twenty years after the government broke up the longstanding MA Bell monopoly, the re-monopolization of telecommunication is almost done. This is the worst consequence of the Act. Telecom market is facing the same position as it faced twenty years back. The companies have regained their vertical structure and are edging the whole market towards a monopolistic state.

\section{Section 271 Checklist}

In return for opening their markets to competition, the Telecom Act allowed RBOCs to enter interstate longdistance markets, which had been prohibited since the 1984 breakup of AT\&T. The Telecom Act's Section 271 provided a 14-point checklist incumbent RBOCs must satisfy before they are allowed into interstate markets. The checklist consisted of specific market-opening actions, such as providing non-discriminatory access to UNEs. The approval process requires that RBOCs apply for 271 approval on a state-by-state basis, and begins by receiving state-regulator certification that section 271's checklist has been satisfied.

Following are the major points of the checklist.

1. The BOC must allow requesting carriers to physically link their communications networks to its network for the mutual exchange of traffic. To do so, the BOC must permit carriers to use any available method of interconnection at any available point in the BOC's network. Interconnection between networks must be equal in quality whether the interconnection is between the BOC and an affiliate, or the BOC and competing local carrier.

2. The BOC must provide a connection to network elements at any technically feasible point under rates, terms, and conditions that are just, reasonable and nondiscriminatory. Non-discriminatory access to OSS (systems, databases, and personnel) is required to facilitate nondiscriminatory access to network elements.
3. The BOC must show that competitors can obtain access to poles, ducts, conduits, and rights-of-way within reasonable time frames and on reasonable terms and conditions, with a minimum of administrative costs, and consistent with fair and efficient practices.

4. The BOC must demonstrate that it has a concrete and specific legal obligation to furnish loops on an unbundled basis and that it is currently doing so in the quantities that competitors reasonably demand and at an acceptable level of quality.

5. The BOC must provide competitors with the transmission links on an unbundled basis that are dedicated to the use of that competitor as well as links that are shared with other carriers, including the BOC.

6. The BOC must provide Unbundled Local Switching to the competitors.

7. The BOC must provide competing carriers with accurate and nondiscriminatory access to 911 and E911 so that competitors' customers are able to reach emergency assistance, directory assistance and operator services.

8. White pages listings for customers of different carriers are comparable, in terms of accuracy and reliability, notwithstanding the identity of the customer's telephone service provider.

9. The BOC must provide other carriers with the same access to new NXX codes within an area code that the BOC enjoys.

10. The BOC must demonstrate that it provides competitors with the same access to the call-related databases and associated signaling that it provides itself.

11. The BOC must demonstrate that it provides number portability to competing carriers in a reasonable time frame.

12. The BOC must establish that customers of another carrier are able to dial the same number of digits to make a local telephone call. In addition, the dialing delay experienced by the customers of another carrier should not be greater than that experienced by customers of the BOC.

13. The BOC must compensate other local carriers for the cost of transporting and terminating a local call from the BOC. Alternatively, the BOC and competing carrier may enter into an arrangement whereby neither of the two carriers charges the other for terminating local traffic that originates on the other carrier's network.

14. The BOC must offer other carriers all of its retail services at wholesale rates without unreasonable or discriminatory condition or limitations such that other carriers may resell those services to an end user.

Role of FCC 
FCC approved the first 271 application, Verizon's New York application, in December 1999, nearly four years after the Act's passage.

As July 1, 2002, the FCC had approved 271 applications in Arkansas, Connecticut, Georgia, Kansas, Louisiana, Massachusetts, Maine, Missouri, New Jersey, New York, Oklahoma, Pennsylvania, Rhode Island, Texas and Vermont. The FCC was in the process of reviewing applications from Alabama, Kentucky, Mississippi, North Carolina, South Carolina, New Hampshire and Delaware. RBOCs received 271 approvals for all of their states by December 2003 [19].

There was a vast difference between what the fourteenpoint checklist says FCC should do, and what it allows the FCC to do. The opinion of FCC was that the Commission must apply the terms of the competitive checklist strictly as they were written, as the FCC did not write the law. Still FCC's Local Competition Order contains hundreds of pages of binding law on the meaning of 11 of the 14 checklist items. For example the Local Competition Order contains no less than 20 paragraphs discussing what it means to provide unbundled local loops. The whole situation was severely troubled by the extent of detail in which FCC had immersed itself in administering the fourteen-point checklist. The Commission vastly expanded the fourteen-point statutory checklist to include a plethora of new sub elements. All this happened because Section 271 permitted an incredible degree of FCC micromanagement.

\section{Role of RBOCs}

RBOCs always insisted that each rulemaking and decision added to or altered the compliance requirements, sometimes very significantly. The continually evolving nature of these requirements was a major problem. The costs associated with meeting these requirements constituted a significant barrier to RBOC entry into the interLATA market. This was like a never receding finish line for their entry into the long distance market.

RBOCs refused to accept the performance standards and performance penalties that the Department of Justice identified as necessary to ensure non-discrimination on an ongoing basis and continued a legal battle. Once RBOCs got the permissions they started mergers and acquisitions. Eight large carriers of 1996 have reduced to just four now.

\section{Role of AT\&T and other long distance companies}

The long distance carriers - AT\&T, MCI and Sprint were thought to be the most likely entrants into local services but they were very slow to move. They used this slow progress to argue against any attempt by RBOBs to enter the long distance market, and they did this successfully in every case filed. FCC refused to approve RBOCs applications for inter LATA services on the grounds that they have failed to comply with some aspects of the required competitive checklist.

Long distance companies used every tactic to stop RBOCs from entering the lucrative long distance services. They did not make any crucial investments in local infrastructure just to stop RBOCs from entering their market.

\section{Results}

Following are the results of section III, IV and V.

1. Since the approval of Act in 1996, CLECs have not been able to increase their share of the market. They have tried to enter the market but still their part is limited and most of the network is still held by ILECs.

2. The market of local telephony has moved to little bit of competition but at very slow pace.

3. RBOCs still hold a monopoly or near monopoly positions in their areas.

4. As evident from graph 4, percentage of CLEC owned infrastructure based lines remains the same, thus showing that CLECs have not made any crucial investment.

5. RBOCs have extended their monopoly to the long distance markets.

6. There is a wave of mergers and acquisitions as a result of Telecom Act distorting the whole market.

7. RBOCs have re monopolized and re grouped.

8. Residential Area is mostly neglected by CLECs.

9. Coaxial cable has failed as substitute for twisted pair based infrastructure.

10. The subscribers are unable to receive the benefits of technological advances due to unregulated monopolization in local market.

11. Congress intended to write a pro competitive, deregulatory law but did not do so. Telecom Act's proponents did not understand the realities of the telecom market and the incentives of the multibillion-dollar corporations in it. A law that seemed simple and spare when Congress wrote it became impossibly complicated and over regulatory when the FCC implemented it.

12. Each of the14 points on the checklist became a point of contention, friction, and delay.

13. This list helped the long distance carriers and clearly slowed entry of RBOCs into long distance market for a number of years. Once RBOCs got entry, they jeopardized the whole market by mergers and acquisitions.

We can say that

The telecommunication Act 1996 has failed to achieve its goal of achieving full competition in all markets even 
after 10 years. It has been able to induce very little competition especially in the last mile at very slow pace. RBOCs still hold a monopoly or near monopoly positions in their areas. As a result of mergers and acquisitions they have re monopolized and vertically re integrated. FCC, RBOCs and long distance companies all were responsible for the failure of the 14-point checklist. Hence it is hard for the subscribers to receive the full advantages of technology developments.

In the next section we shall take a detailed look at the reasons of failure of telecom Act.

\section{Reasons for Failure}

Following are the major reasons for failure of Telecom Act 1996.

\section{Local loop is a natural monopoly}

Telecom Act failed because it took the wrong direction. The intentions were right to provide fruits of technology development to the consumers but the approach was wrong.

In local loop duplication does not bring additional utility whereas additional cost is tremendous. The local loop is a natural monopoly just like water companies. Monopoly in local telephony segment is very difficult to break due to high economies of scale.

The basic error was the breaking of local monopoly as even after 10 years, Bell companies are still monopolies in their regions. In most of the regions they have consolidated their positions.

\section{Investments in local loop is not required}

There is no need of more investment in local loop as it will only create duplication.

In 1996 about $95 \%$ of houses had the access to telephone service [20]. As the access rate is so high, creating competition simply means duplication of infrastructure or reselling of the same facilities.

Most of the subscribers don't need more than one line in their houses. Hence the Act has created unregulated monopolies in the local Telephony market. Unregulated local monopolies are worse than regulated monopolies as they pose a threat for numerous information and communication technology markets that might otherwise be deemed to be effectively competitive.

\section{UNE pricing with TELRIC}

The Act required the incumbent operators to provide competitors access to parts of their network.

FCC was assigned the responsibility to decide exactly which parts to be offered. From here the problem started. FCC made a comprehensive list of UNEs including switches, transport lines and local loop. The list included all the facilities of incumbent operator to be provided to the competitors at price set by regulators. The Act called the price to be just and reasonable. FCC calculated the prices using TELRIC. TELRIC is a forward looking costing method which includes the incremental cost resulting from adding or subtracting a specific network element. TELRIC introduced low prices for UNEs.

The availability of UNEs from incumbent carriers at low regulated prices distorted the market. It created a 'make vs. buy' trade-off for competitors. They decided to lease vital equipment rather than making the expensive and risky investments in making their own infrastructure [21].

This created a second best sort of competition with competition among the firms sharing the same infrastructure at artificially low rates ordered by regulators.

This also hindered the new investment as it discouraged incumbent carriers from investing in their networks since benefits have to be shared with rivals. Overall incumbent investment had been $\$ 15$ billion less than it would be without these rules [22].

\section{Least regulatory control}

The regulatory control over the monopoly has been released in the Act. The Act envisioned a totally competitive market and did not provide regulatory controls in case competition is not healthy enough. Unregulated control of the local loop bottleneck has posed a severe risk for the telecom sector.

Without regulation, the monopoly pricing always results in substantial deadweight losses and may block the emergence of innovative services. Thus absent regulation of the ILEC bottleneck has been a threat to consumer surplus and overall efficiency as deadweight losses are likely to be large. The abuse of market power has adversely impacted competition all along the value chain of information technology that depends on PSTN.

\section{Universal Service}

The most disastrous and useless section of the Act were those that dealt with the universal service.

Congress gave FCC more power to create havoc in the market in the name of social justice and expansion of social welfare. The policymakers failed to eliminate or make radical reforms in subsidization methods used for universal service.

Current subsidization policies redistribute money in highly inefficient manner to provide cheap local service to all. These subsidies flow from long distance to local users, from business to residential users and from urban to rural users. This mechanism was created to favor AT\&T to strengthen its monopoly power. But in competition these subsidies have destroyed the market structure 
by discouraging market entry since it is always difficult to compete with subsidized firms [23-26].

\section{Self contradiction}

On one side the Act advocates new investment but on the other side it allows UNE pricing by TELRIC which discourages both incumbents and new comers to invest. On one side the Act calls for competition but on the other side it promotes universal service which itself promotes monopolization.

\section{Conclusion}

The Telecommunication Act 1996 was considered as a break through in the telecom market. It has failed to achieve its goals. Vertical reintegration, mergers, acquisitions and re monopolization are major fallouts of the Act. Section 271 also proved to be regulatory mistake over the last 10 years. There are multiple reasons of this failure. Monopoly breaking, UNE pricing and universal service are some of the reasons. As a result RBOCs have consolidated their monopoly positions in most of the areas. Rapid developments in telecommunication now demand innovation in regulatory regime.

\section{REFERENCES}

[1] Samuelson A. Paul, Nordhaus D. William (1995). “Economics.” McGRAW HILL Inc., pp. 154.

[2] Pindyck S. Robert , Rubinfeld L. Daniel (1998). "Microeconomics." Prentice Hall International Inc., pp. 353.

[3] Varian R. Hal (1992). "Intermediate Microeconomics - A modern Approach.” W.W. Norton \& Company, pp. 430.

[4] Woroch A. Glenn (2002). "Local Network Competition.” Handbook of Telecommunication Economics, Elsvier, 2002.

[5] Bomsel Olivier \& Blanc G.L. (1999). "System growth in the US telecom industry: Analysis of the technical, industrial and regulatory process in the US telecom industry.”Advanced Workshop in Regulation and Competition, Newport, USA, May 26-28, 1999.

[6] http://www.fcc.gov/Bureaus/OSEC/library/legislativ e_histories/47.pdf

[7] http://www.fcc.gov/Bureaus/OSEC/library/legislativ e_histories/40.pdf

[8] Goldstein, Fred R. (2005). "The great telecom meltdown.” Artech House, Inc., pp. 20.

[9] AT\&T. "Milestones in AT\&T History.” Available at http://www.corp.att.com/history/milestones.html

[10] AT\&T. "Brief History: The Bell System.” Available at http://www.corp.att.com/history/history3.html

[11] Nicholas Economides (1997). “The Telecommunica- tions Act of 1996 and its Impact.” The Annual Telecommunications Policy Conference, Tokyo, Japan, December 4, 1997.

[12] AT\&T. “A Brief History: Post Divestiture.” Available at http://www.corp.att.com/history/history4.html

[13] Teece D. (1995). “Telecommunication in Transition: Unbundling, reintegration and competition.” Center for research in Management, University of California, Berkeley.

[14] John R. Richard (2006). "Postal Networks and American Telecommunications.” XIV History Congress, Helsinki Finland, 2006 Session 107.

[15] Congress (1996). “Telecommunications Act of 1996, Pub. LA. No. 104-104, 110 Stat. 56 (1996).” Available at http://www.fcc.gov/Reports/tcom1996.pdf

[16] FCC, Industry Analysis and Technology Division, Wireline Competition Bureau (2007). "Local TelephoneCompetition: Status as of December 31, 2005." available at http://hraunfoss.fcc.gov/edocs_public/attachmatch/ DOC-279231A1.pdf

[17] FCC, Industry Analysis and Technology Division, Wireline Competition Bureau (2007). Trends in Telephone Service. Available at http://hraunfoss.fcc.gov/edocs_public/attachmatch/ DOC-270407A1.pdf

[18] Congress (1996). "Section 271(C)(2)(B), Telecommunications Act of 1996, Pub. LA. No. 104-104, 110 Stat. 56(1996).”Available at http://www.fcc.gov/Reports/tcom1996.pdf

[19] www.fcc.gov/Bureaus/Common_Carrier/inregion_a pplications

[20] FCC, Industry Analysis and Technology Division, Wireline Competition Bureau(2006). "Telephone subscribership in united states.” Available at http://hraunfoss.fcc.gov/edocs_public/attachmatch/ DOC-268003A1.pdf

[21] Randolph J. May \& Larry F. Darby (2002). “Comments of the Progress and Freedom Foundation Before the Federal Communications Commission, Review of the Section 251 Unbundling Obligations of Incumbent Local Exchange Carriers. CC Dkt. No. 01-338” (filed April 5, 2002).

[22] Eisenach A. Jeffrey, Lenard M. Thomas (2003). "Telecom Deregulation and the Economy: The Impact of "UNE-P" on Jobs, Investment and Growth." The Progress and Freedom Foundation Release 10.3 .

[23] Grandall W. Robert, Waverman L. (2000). "Who Pays for Universal Service.” Brookings Institution Press, pp. 47.

[24] Turner S. Derek (2006). "Universal Service Reforms \& Convergence: USF policy for the $21^{\text {st }}$ century." $34^{\text {th }}$ research conference on communication, Information and Internet Policy (TPRC) (Sept. 29 - Oct. 1, 2006) Arlington, VA. 
[25] Rosenberg Edwin, Perez-Chavolla Lilia, Liu Jing (2006). "Universal Service." The National Regulatory Research Institute.

[26] Gifford L. Raymond, Peters M. Adam, Riordan H.
Michael (2005). "Digital Age Communication Act : Proposal of the universal service working group, release 2.0.” The Progress and Freedom Foundation.

\section{AUTHORS’ BIOGRAPHIES}

Kashif Azim Janjua, is currently doing his Ph.D. in management sciences and engineering from beijing university of posts and telecommunications, Beijing, China. He did his masters in computer engineering and bachelors in electrical engineering from university of engineering and technology, Lahore, Pakistan. His research interests include firm organization theories, transaction cost economics, vertical integration and regulation.

Sahibzada Ahmed Noor, is currently doing his masters in telecommunication and information and systems from the beijing university of posts and telecommunications Beijing, China. He did his bachelors in software eng from shenyang instituite of chemical engineering, Shenyang, China. His research interests include mobile networks, MIPv6 and data processing using Microsoft tools.

Shahzada Alamgir Khan, is currently doing his Ph.D. in management sciences and engineering from beijing university of posts and telecommunications, Beijing, China. He did his masters in electononis engineering and bachelors in electrical engineering from university of engineering and technology, Taxila, Pakistan. Research interests include universal service issues in telecommunication and history of telecommunication. 